Revista de la red interuniversitaria de estudios sobre las literaturas rioplatenses contemporáneas en Francia

$18 \mid 2018$

El río y la ciudad

\title{
El Riachuelo
}

Martín Kohan

\section{OpenEdition}

Journals

\section{Edición electrónica}

URL: http://journals.openedition.org/lirico/5711

DOI: 10.4000/lirico.5711

ISSN: 2262-8339

Editor

Réseau interuniversitaire d'étude des littératures contemporaines du Río de la Plata

Referencia electrónica

Martín Kohan, «El Riachuelo », Cuadernos LIRICO [En línea], 18 | 2018, Puesto en línea el 14 octubre 2018, consultado el 03 mayo 2019. URL : http://journals.openedition.org/lirico/5711 ; DOI : 10.4000/ lirico. 5711

Este documento fue generado automáticamente el 3 mayo 2019.

\section{(c) $(1) \Theta \Theta$}

Cuadernos LIRICO está distribuido bajo una Licencia Creative Commons Atribución-NoComercialSinDerivar 4.0 Internacional. 


\title{
El Riachuelo
}

\author{
Martín Kohan
}

Ese río ni nombre tiene. Porque dio en llamarse "Riachuelo", que es más una designación que un nombre, que es un sustantivo común (porque el río es eso: común) antes que un sustantivo propio (porque el río nada tiene de propio). Llamarlo "riacho", decirle "riacho", habría supuesto ya de por sí una disminución; "riachuelo" implica entonces una doble reducción, decirle al río dos veces que es pequeño, que es menor, que es poca cosa. El Riachuelo tiene pues la impronta de lo desestimado: la fuerza de lo desestimado. Sin eso su paisaje no sería lo que es.

El Riachuelo es un riachuelo respecto del río mayor, que es el Río de la Plata. Cuando se afirma, como es costumbre afirmar, que "Buenos Aires le da la espalda al río", en el sentido de lo poco que se conecta e interactúa con él, se da automáticamente por sobreentendido que el río del que se habla es el Río de la Plata. Lo que viene a demostrar que el río al que verdaderamente se omite, al que de verdad se olvida, el río al que Buenos Aires le da la espalda de veras, no es otro que el Riachuelo. Porque en el Riachuelo no se piensa ni siquiera para establecer el lugar común del dar la espalda, la orilla de la que se desiste para vivir por convicción en la ficción de lo mediterráneo.

El Río de la Plata es fabulosamente ancho, tanto que, desde una orilla, no alcanza a divisarse la otra. Por eso sus descubridores lo llamaron al principio "Mar Dulce". Y se adentraron en él porque lo supusieron un posible canal de pasaje del Atlántico al Pacífico, la tan ansiada comunicación de un lado al otro del mundo. Acabaron por bautizarlo De la Plata, así como el país, bajo esa misma ilusión de riqueza, dio en denominarse Argentina. A Buenos Aires, los que la veneran, la exaltan como "la Reina del Plata". Al Riachuelo, en cambio, por su parte, no hizo falta ni descubrirlo, no tiene su Juan Díaz de Solís. Si alguno se adentró alguna vez, fue porque quiso; el río no prometía nada, ni conductos interoceánicos ni riquezas inconcebibles. No constituye una región, como lo "rioplatense", sino apenas aledaños. $\mathrm{Y}$ de reinas y reinados, ni hablar: puras mendicidades. No existe nada más plebeyo, más profano y más vulgar que él.

Nadie se baña en este río. Ni dos veces, como dijo Heráclito, ni una sola. No es posible ni pensarlo porque está, desde hace mucho, mortalmente contaminado. El Riachuelo corre en su mayor parte por una geografía de desechos, hasta convertirse, él mismo, en el lugar de los desechos. Buenos Aires empujó hacia sus orillas casi todo lo que descartaba, y las 
industrias hicieron lo mismo, hasta hacer del río una corriente de agua tóxica. Se lo fue envenenado sin parar a lo largo de los años; ahora es, él mismo, veneno puro.

Cargado de indecencias, desembocó en el Río de la Plata y lo contaminó a su vez. ¿Venganza postrera? ¿Piedrazo a Goliath? El Río de la Plata se forma con la espléndida confluencia de los ríos Uruguay y Paraná. El Paraná baja formando un delta y ese delta abunda en pintoresquismos y mitos que lo favorecen. El norte de Buenos Aires asiste a esos prestigios y los enriquece diariamente con veleros y paseos y preciosas vistas costeras. Es, en cambio, desde el sur desde donde brota el Riachuelo, y le asesta sus aguas pútridas al Río de la Plata, lo infesta consigo mismo, lo infesta de sí mismo.

Hacia fines del siglo XIX, hubo que delimitar el contorno de la ciudad de Buenos Aires. Fundada desde el siglo XVI, no estaba todavía delimitada (en su "Fundación mítica de Buenos Aires", Borges menciona al Riachuelo y alude al Plata: la primera fundación, la que no prosperó, parece haberse verificado más cerca del primero; la segunda, la que salió bien, más cerca del segundo). Surgió hacia 1880 el proyecto de trazar los límites de Buenos Aires de tal modo que el Riachuelo la recorriera de lado a lado, más o menos por el medio. Lo que suponía, de por sí, disponer sucesivos puentecitos por los que ir y venir y asomarse, riberas cordiales por las que andar, las bondades de los ríos integrados al tejido urbano. Fue la chance que tuvo el Riachuelo de emular, así fuera remotamente, desde la periferia más insignificante del mundo, al Sena o al Tíber, al Támesis o al Spree.

Pero no fue eso lo que sucedió. La resolución que primó fue esta otra, bien distinta: que el Riachuelo mismo sirviera de límite para Buenos Aires. No una parte de la ciudad, sino más bien su frontera: el lugar donde todo se acaba (no donde empieza, sino donde acaba); el lugar hacia el cual la ciudad declina, donde cesa y se apaga y se olvida. El Riachuelo quedó así dispuesto para ser atravesado, en un sentido o en otro, para llegar a Buenos Aires o para salir de Buenos Aires, pero no para ser bordeado o recorrido. Si el Plata, como tituló Juan José Saer, es el río sin orillas, el Riachuelo vendría a ser el río-orilla. Ni el río sin orillas ni el río con orillas (pues, ¿qué hay en sus orillas?: yuyos, descartes, mugre, miseria), sino el río que sirve de orilla en sí mismo: orilla de la ciudad. Sirve para eso, para cortar y para separar. A diferencia del vasto Río de la Plata, desde un lado alcanza a verse el otro, alcanza a verse, sí, ahí nomás. Y sin embargo, nadie mira, porque no hay nada para ver.

El río carece de nombre, en el sentido más fuerte del término, pero ha sabido dar un nombre, y uno de la mayor importancia. Porque el pasaje entre el Riachuelo y el Plata, la transición de esa desembocadura, es "la boca del Riachuelo". Y esa boca produjo un nombre, "La Boca", que es un barrio de poderosa identidad en la ciudad de Buenos Aires (tanto como para que llegara a autoproclamarse República). Ese nombre, a su vez, engendró otro, "Boca Juniors", que es el club de fútbol más grande de la Argentina, uno de los más importantes del mundo.

El Río de la Plata, con toda su presunta imponencia, no fue capaz de suscitar algo así de trascendente. Ni siquiera recurriendo al inglés, en torpe procura de un halo de sofisticación.

Hay un recodo del Riachuelo, ahí en el barrio de La Boca, que se llama Vuelta de Rocha. Se intentó, hace unos años, formarle una costanera, despejar y decorar su ribera para hacerla hospitalaria. Que yo sepa, sirvió de poco: el río hosco se las arregló para hacer prevalecer lo inhóspito. La geografía del abandono impera y, si no impera, al menos acecha. En el río flotan basuras y lamparones violáceos de aceite, los barquitos esporádicos que puedan pasar en un sentido o en otro lo hacen como si estuviesen empujando algo para lograr abrirse paso, apartando obstáculos, surcando lo espeso. Nadie 
pesca en el Riachuelo, porque no hay vida para sacarle. No hay razones para asomarse a él, y de hecho raramente alguien lo hace.

Con la visión panorámica, distanciada y general, la contemplación del Riachuelo mejora, pero mejora porque se atempera, porque se filtra y porque vira de lo concreto hacia lo abstracto. Un museo muy coqueto se inauguró hace ya unos veinte años justamente ahí, en plena Vuelta de Rocha, entre los galpones inhóspitos y los desolados callejones de empedrado antiguo. Desde los ventanales de ese museo, el Riachuelo puede verse como si fuese una postal, que es justo lo que no es. La mirada abarcativa lo adecenta, porque sirve para omitir los detalles desdorosos y de paso también el olor (pues si hay algo que identifica al Riachuelo, es el olor).

La lejanía, así forjada, no sirve para realzar el río, sino más bien para neutralizarlo. Aunque parezca abrirse hacia él, tanto como los ventanales, lo que hace es rehuirlo, apartarse, retroceder. Lo mismo que la ciudad, para el caso.

El barrio de La Boca es mayormente pobre (pobreza que, por tradición, es disfrazada de tipicidad y usada para concitar la presencia de turistas). Sufrió por largo tiempo oprobiosas inundaciones; el agua agresiva subía y entraba, sin clemencia, estropeando lo ya estropeado. Por esa razón, buena parte de las casas y las veredas del barrio de La Boca está construida en altura, siete $u$ ocho escalones por encima del nivel de la calle. Son tan típicas esas elevaciones como lo es la propia miseria. Y es que eran tan típicas esas inundaciones, que hasta había estribillos sobre el tema coreados en las tribunas de fútbol por puro afán de menosprecio.

Solucionado el tema de las inundaciones, que ya no ocurren más en esa zona de Buenos Aires sino en otras, las veredas en elevación persisten en La Boca como un reflejo defensivo frente a un peligro ya caducado. Quedó eso, el gesto de prevención, pero nada de aquello de lo que había que prevenirse; quedó la huella de un viejo temor, pero nada de aquello que resultaba temible. No es el Riachuelo, por ende, lo que aquí se exhibe y se ve, sino en todo caso su ausencia. Su presencia en el pasado y su ausencia en el presente. El Riachuelo por la negativa, podría decirse entonces. Señalado por la falta, como una de sus tantas versiones posibles.

Buenos Aires, en general, desatiende al Riachuelo, lo mira poco o de lejos; lo deja solo, corriendo al fondo. Pero a cambio, en una especie de voluntad de redención estética, lo aprecia cuando lo pinta Benito Quinquela Martín. En las pinturas de Quinquela Martín (pero nunca como en ellas) el Riachuelo es valorado y hasta admirado, se lo eleva incluso al nivel del emblema urbano

Quinquela concibió al Riachuelo como espacio de trabajo. Lo pobló de barcos y de planchones y de hombres encorvados por el peso de las mercancías cargadas en la espalda. En el horizonte, las columnas de humo (sinuosas) y las chimeneas de las fábricas (rectas); en el río, las ondas del agua (sinuosas) y los mástiles de las embarcaciones (rectos): la plena laboriosidad impera, el Riachuelo está ahí para que se lo trajine y trajine. Estas resueltas visiones portuarias sirven para dar sentido al gentilicio de los habitantes de Buenos Aires. Porque los porteños nos sabemos porteños y nos decimos porteños, pero en el puerto que motivó ese nombre no reparamos casi nunca.

Pero existe además un tango (grabado, entre otros, por Tita Merello, por Edmundo Rivero, por Roberto Goyeneche) que sirve de validación artística al Riachuelo. Es Nieblas del Riachuelo, con música de Juan Carlos Cobián y letra de Enrique Cadícamo. En vez de asociarlo con el transcurso y con los cambios, como parecería propiciarlo un río, Cadícamo inscribe al Riachuelo en el imperio de lo definitivo: en el "para siempre" y en el "nunca más" ("barcos que en el muelle para siempre han de quedar", "anclas que ya 
nunca, nunca más han de levar"), expresión desplazada del drama de amor que subyace ("de ese amor para siempre me vas alejando", "nunca más volvió... nunca más la vi”).

El Riachuelo, más que un curso para navegar, es un sitio para fondear (es un "turbio fondeadero"), para recalar y amarrar y quedarse. Los sueños de mar van a frustrarse, porque estos barcos del Riachuelo ya "jamás han de zarpar" (tal y como el enamorado, que está "amarrado al recuerdo"). El Riachuelo como un lugar sin salida, como atadura y como fijación, se convierte con Cadícamo en la expresión cabal de lo definitivo: "torvo cementerio de las naves que al morir / sueñan sin embargo que hacia el mar han de partir". De acá no se sale, porque es un cementerio; este río es un recinto de muerte, este río es la muerte misma.

¿Lo opuesto o lo complementario de la vitalidad del trabajo en Benito Quinquela Martín? No lo sé.

Aguas arriba, el Riachuelo cambia de nombre (o toma uno). Pasa a llamarse río Matanza. 